Gut and Liver, Vol. 9, No. 3, May 2015, pp. 332-339

\title{
Bile Acid Diarrhea: Prevalence, Pathogenesis, and Therapy
}

\author{
Michael Camilleri \\ Clinical Enteric Neuroscience Translational and Epidemiological Research (C.E.N.T.E.R.), Mayo Clinic College of Medicine, Rochester, MN, USA
}

Bile acid diarrhea (BAD) is usually seen in patients with ileal Crohn's disease or ileal resection. However, $25 \%$ to $50 \%$ of patients with functional diarrhea or diarrhea-predominant irritable bowel syndrome (IBS-D) also have evidence of BAD. It is estimated that $1 \%$ of the population may have BAD. The causes of BAD include a deficiency in fibroblast growth factor 19 (FGF-19), a hormone produced in enterocytes that regulates hepatic bile acid (BA) synthesis. Other potential causes include genetic variations that affect the proteins involved in BA enterohepatic circulation and synthesis or in the TGR5 receptor that mediates the actions of BA in colonic secretion and motility. BAs enhance mucosal permeability, induce water and electrolyte secretion, and accelerate coIonic transit partly by stimulating propulsive high-amplitude colonic contractions. There is an increased proportion of primary BAs in the stool of patients with IBS-D, and some changes in the fecal microbiome have been described. There are several methods of diagnosing BAD, such as ${ }^{75}$ selenium homotaurocholic acid test retention, serum C4, FGF-19, and fecal BA measurement; presently, therapeutic trials with BA sequestrants are most commonly used for diagnosis. Management involves the use of BA sequestrants including cholestyramine, colestipol, and colesevelam. FXR agonists such as obeticholic acid constitute a promising new approach to treating BAD. (Gut Liver 2015;9:332-339)

Key Words: Malabsorption; FGF-19; FXR; C4; CYP7A1; Klotho $\beta$

\section{INTRODUCTION: BILE ACIDS, FAT ABSORPTION, AND THE ENTEROHEPATIC CIRCULATION}

Bile acids (BAs) are detergent molecules ${ }^{1}$ that are synthesized in the liver and are responsible for solubilization of fatty acids and monoglycerides (the lipolysis products of triglycerides), facilitating digestion and lipid absorption in the small intestine. The different BA molecules are differentiated by hydroxylation and conjugation. Chenodeoxycholic acid (CDCA) and cholic acid (CA) are primary BAs synthesized from cholesterol and conjugated with taurine or glycine in the liver; in the colon, bacteria deconjugate and dehydroxylate the BAs to form, respectively, lithocholic acid and deoxycholic acid (DCA). ${ }^{2}$

Taurine or glycine conjugation of the BAs permits the ionization of BAs which increases their solubility and their impermeability to cell membranes, allowing BAs to reach the critical micellar concentration for spontaneous formation of micelles. In the micelles, the polar BAs surround the insoluble, hydrophobic fatty acids and monoglycerides and present the hydrophobic fat molecules to the enterocyte brush border membrane of the small intestine for digestion and absorption.

The apical $\mathrm{Na}^{+}$-dependent bile salt transporter (ASBT) (also called ileal BA transporter or SLC10A2 [solute carrier family 10, member two]) is responsible for the active reuptake of BAs in the terminal ileum. This reabsorbs approximately 95\% of BAs in the terminal ileum and results in a functional enterohepatic circulation of $\mathrm{BA},{ }^{3}$ transporting the BAs back to the liver. Several molecular mechanisms are involved in the enterohepatic circulation: farnesoid X receptor (FXR) is expressed in ileal enterocytes and hepatocytes; BAs are agonists of the FXR; sensing of the enterocyte BA pool by FXR affects the liver by way of the endocrine factor, fibroblast growth factor 19 (FGF-19); FGF-19 is released from enterocytes into the portal circulation and activates FGF receptor 4 (FGF-R4) in hepatocytes in a process that involves interaction with klotho $\beta$ on the hepatocyte membrane, resulting in downregulation of cholesterol $7 \alpha$-hydroxylase (CYP7A1) and therefore inhibition of the BA synthesis. Cholerheic or BA diarrhea is thought to result predominantly from the interruption of the enterohepatic circulation. ${ }^{3}$

\footnotetext{
Correspondence to: Michael Camilleri

Clinical Enteric Neuroscience Translational and Epidemiological Research (C.E.N.T.E.R.), Mayo Clinic College of Medicine, 200 First St. S.W., Charlton Bldg., Rm. 8-110, Rochester, MN 55905, USA

Tel: +1-507-266-2305, E-mail: camilleri.michael@mayo.edu Received on October 14, 2014. Accepted on November 10, 2014. pISSN 1976-2283 eISSN 2005-1212 http://dx.doi.org/10.5009/gnl14397

@ This is an Open Access article distributed under the terms of the Creative Commons Attribution Non-Commercial License (http://creativecommons.org/licenses/by-nc/3.0) which permits unrestricted non-commercial use, distribution, and reproduction in any medium, provided the original work is properly cited.
} 


\section{CLASSIFICATION OF BILE ACID MALABSORPTION/ DIARRHEAS}

The causes of BA diarrhea (BAD) are based on the original classification of BA malabsorption (BAM):

Type 1: Ileal dysfunction and impaired reabsorption, e.g., Crohn's disease

Type 2: Primary, or idiopathic, BAD produces a similar picture of increased fecal BAs, watery diarrhea, and response to BA sequestrants in the absence of ileal or other obvious gastrointestinal disease

Type 3: Other gastrointestinal disorders which affect absorption, such as small intestinal bacterial overgrowth, celiac disease, or chronic pancreatitis

A fourth category of BAD may result from excessive hepatic BA synthesis; for example, the oral hypoglycemic drug, metformin, is associated with increased hepatic BA synthesis. ${ }^{4-6}$

\section{WHAT'S NEW IN UNDERSTANDING THE ETIOPATHOGEN- ESIS OF IDIOPATHIC BILE ACID DIARRHEA?}

Recent literature has identified several novel potential mechanisms in the development of idiopathic BAD (Fig. 1). ${ }^{7}$

\section{Defective feedback inhibition of bile acid biosynthesis by FGF-19}

FGF-19 produced in the ileum in response to BA absorption regulates hepatic BA synthesis. ${ }^{8}$ In a landmark article, Walters et al. ${ }^{9}$ reported lower serum FGF-19 in patients with BAM and an inverse relationship between FGF-19 and serum C4 (a surrogate of the rate of hepatic BA synthesis). These results were replicated by others. ${ }^{10,11}$

\section{Genetic mutations in the apical sodium-bile acid trans- porter}

Genetic mutations in the apical sodium-bile acid transporter (ASBT) are extremely rare. ${ }^{12,13}$ In addition, defective BA uptake into ileal mucosal biopsies was excluded by Bajor et al. ${ }^{14}$

\section{Accelerated small bowel transit bypassing active bile acid transport in the ileum}

Accelerated small bowel transit bypassing active BA transport in the ileum has been hypothesized as a cause of BAM in idiopathic ${ }^{15}$ and postradiation cases. ${ }^{16,17}$ While this is theoretically possible, it seems unlikely given the ASBT's affinity for BA, and it is unclear whether the accelerated small bowel transit is a cause or an effect of the BAM.

\section{Genetic variations in the proteins involved in feedback regulation of bile acid synthesis, specifically KlothoB gene and fibroblast growth factor 4 gene}

The role of these genetic variants is based on significant associations of SNP rs17618244 in the KlothoB (KLB) gene with colonic transit in diarrhea-predominant irritable bowel syn-

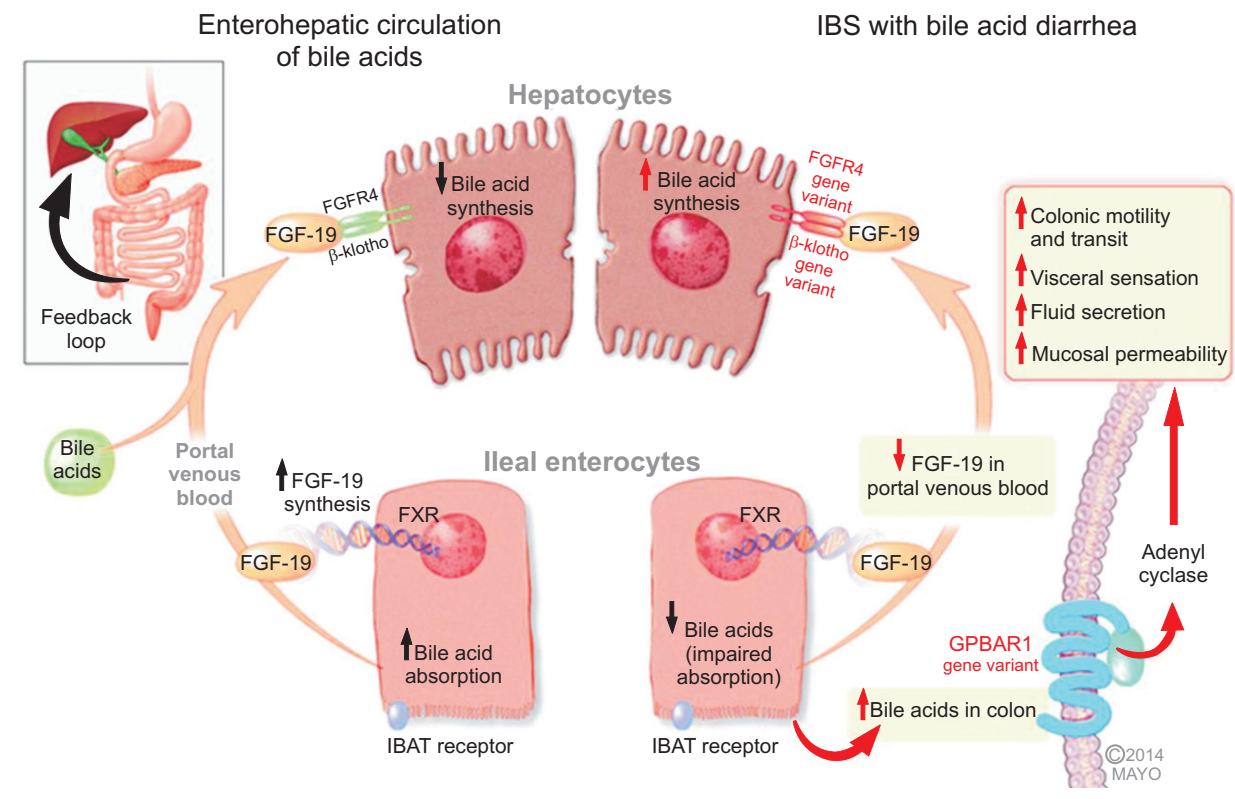

Fig. 1. Mechanisms of bile acid (BA)-related bowel dysfunction in irritable bowel syndrome with diarrhea (IBS-D) or idiopathic BA diarrhea (Adapted from Camilleri M. J Physiol 2014;592(Pt 14):2967-2980). ${ }^{7}$ Enterohepatic circulation of bile acids: Ileal enterocytes absorb bile acid through a receptor-mediated process (ileal bile acid transporter [IBAT]). Intracellular bile acids activate the farnesoid- $\gamma$ receptor to increase fibroblast growth factor 19 (FGF-19) synthesis. FGF-19 in the portal circulation downregulates hepatocyte bile acid synthesis. Disorders of FGF-19 synthesis by ileal enterocytes or genetic variations of FGFR4 or $\beta$-klotho lead to excess bile acid concentration in the colon, resulting in activation of the G protein-coupled bile acid receptor 1 (GPBAR1, or TGR5) with enteroendocrine cell stimulation (e.g., release of 5-hydroxytryptamine) and stimulation of colonic motility with acceleration of colonic transit, activation of visceral sensation and fluid secretion (through increased intracellular cAMP, increased mucosal permeability or chloride ion secretion). Genetic variation in GPBAR1 (TGR5) is associated with increased colonic transit in IBS-D. 
drome (IBS-D). ${ }^{18}$ Pharmacogenetic studies of the influence of KLB (rs17618244) on the dose-response effects of administered chenodeoxycholate on the emptying rate of the ascending co$\operatorname{lon}^{11}$ suggest that KLB variation may influence colonic response to BAM, and exome DNA sequencing studies showed KLB (rs1015450, downstream) association with fecal BAs and FGFR4 (rs1966265, nonsynonymous) with colonic transit. ${ }^{19}$

\section{Upregulation of the membrane bound bile acid receptor, TGR5 or GPBAR1}

TGR5, or GPBAR1, is a member of the G protein-coupled receptor superfamily that functions as a cell surface receptor for $\mathrm{BA},{ }^{20}$ including colonic epithelial cells, ${ }^{21}$ regulating basal and cholinergic-induced secretion in rat colon ${ }^{22}$ and colonic transit. ${ }^{23}$ We have recently shown that genetic variation in GPBAR1 predisposes to quantitative changes in colonic transit and BA excretion. ${ }^{24}$

\section{CELLULAR MECHANISMS OF BILE ACID DIARRHEA}

BA chemistry determines effects on colonic mucosa; in general, the surface active properties that lead to increased colonic mucosal permeability and electrolyte and water secretion are associated with two hydroxyl groups at the 3,7 (CDCA) or 3,12 (DCA) positions in the $\alpha$-configuration. BAs regulate many cell types in the gut wall and beyond by activating nuclear and plasma membrane receptors. Of these, the G protein-coupled receptor, TGR5, has emerged as a key mediator of the nongenomic actions of BAs. TGR5 is a cell-surface receptor that couples to Gas, formation of cAMP, activation of protein kinase A and extracellular signal-regulated kinases, and inhibition of inflammatory signaling pathways. ${ }^{25}$

The mechanisms of diarrhea include increased mucosal permeability; ${ }^{26}$ water secretion through activation of CFTR via adenylate cyclase $\mathrm{e}^{27,28}$ and inhibition of apical $\mathrm{Cl} / \mathrm{OH}$ exchange; ${ }^{29}$ lubrication by increased mucus secretion (a direct effect on goblet cells); $;^{30,31}$ and acceleration of colonic motility, likely via TGR5 stimulation of myenteric ganglionic neurons. ${ }^{23}$ BAs induce colonic high amplitude propagated contractions. ${ }^{32}$

\section{PREVALENCE OF BILE ACID DIARRHEA}

Type $1 \mathrm{BAD}$ is caused by ileal disease or resection, typically due to Crohn's disease or radiation ileitis. The classical papers of Hofmann and Poley ${ }^{33-35}$ described the association of ileal disease of $<100 \mathrm{~cm}$ length with diarrhea; when the extent of involvement was over $100 \mathrm{~cm}$, there was associated steatorrhea as a result of BA deficiency.

Type 2 BAD is currently considered diarrhea without morphological abnormalities. Several studies have documented BAM in one-third to one-half of patients with chronic diarrhea or IBS$\mathrm{D}$, as summarized in a systematic review. ${ }^{36}$ Overall, the systematic review found that BAM was reported in 32\% of patients with symptoms consistent with IBS-D, and there was a dose-response relationship to treatment with BA binders, based on severity of BAM assessed by ${ }^{75}$ selenium homotaurocholic acid test $\left({ }^{75} \mathrm{SeHCAT}\right)$ retention at 7 days. Similar results were found in recent studies of patients presenting to an outpatient gastroenterology clinic in the United Kingdom ${ }^{37}$ and in a prospective research study at Mayo Clinic of local patients with IBS-D. ${ }^{10,38}$ In fact, the IBS-D patients had evidence of increased fecal BA excretion and increased hepatic BA synthesis.

It has been estimated that $1 \%$ of the population of Western countries suffers from BAD. ${ }^{39}$

\section{INTERACTIONS OF THE MICROBIOME OF THE COLON AND BILE ACIDS}

The colonic microbiome is responsible for the dehydroxylation of cholic and chenodeoxycholic acids to the secondary BAs, deoxycholic and lithocholic acids. Gut microbiota also regulate expression of fibroblast growth factor 15 in the mouse ileum and cholesterol CYP7A1 in the liver by FXR-dependent mechanisms. ${ }^{40}$ The microbiome influences the generation of BAs and other organic acids in the murine colon. ${ }^{41}$ In humans, BA pool size and composition appear to be major regulators of microbiome structure, which, in turn, appears to be an important regulator of BA pool size and composition. ${ }^{42}$ Ongoing research seeks to unravel the contributions of the microbiome and BA composition to diverse conditions including colorectal cancer, ${ }^{43}$ inflammatory bowel disease, ${ }^{44}$ and irritable bowel syndrome. ${ }^{45}$

\section{CHANGES IN THE PROFILE OF FECAL BILE ACIDS IN IR- RITABLE BOWEL SYNDROME}

Several studies have now reported the profile of fecal BAs in patients with IBS-D. Duboc et al. ${ }^{45}$ reported that the percentage of fecal primary BA was significantly higher in IBS-D patients than in healthy controls, and it was significantly correlated with stool consistency and frequency. They also reported a significant increase of Escherichia coli and a significant decrease of leptum and bifidobacterium in IBS-D patients. Shin et al..$^{38}$ confirmed that fecal levels of primary BAs (cholic and chenodeoxycholic [CDCA] acids) were higher in 31 subjects with IBS-D, compared with 30 healthy controls, and also reported that the proportions of fecal secretory BAs (chenodeoxycholic and deoxycholic [DCA] acids) were lower in 30 IBS-C patients compared with controls. An extension study of the latter cohort involving 64 patients with IBS-D confirmed the differences in the proportions of primary and secondary BAs in feces of patients with IBS-D. In addition, the phenotypes of patients with IBS-D and increased total fecal excretion of $>2,337 \mu \mathrm{mol}$ per 48 hours differed from that of IBS-D patients with normal fecal BA excretion, including higher body mass index, increased fecal fat excretion, higher 
proportion of primary BAs (CA and CDCA) in stool, and a trend to faster colonic transit. ${ }^{46}$

\section{DIAGNOSIS OF BILE ACID MALABSORPTION}

Table 1 summarizes the diagnostic tests for BAM and their pros and cons. ${ }^{47}$

\section{Direct measurements of bile acids}

${ }^{14} \mathrm{C}$-glycocholate breath and stool test, ${ }^{75}$ selenium homotaurocholic acid test (SeHCAT), $7 \alpha$-hydroxy-4-cholesten-3-one (C4), and fecal BAs are direct measurements of BAs or surrogates for the rate of hepatic synthesis of BAs, which is proportional to BAM.

The ${ }^{14} \mathrm{C}$-glycocholate $\left({ }^{14} \mathrm{C}\right.$-BA) breath and stool test is based on the principles ${ }^{48}$ that bacterial overgrowth in the small intestine enzymatically degrades the ${ }^{14} \mathrm{C}$-BA, releasing ${ }^{14} \mathrm{C}$-glycine which is absorbed into the portal circulation, is rapidly metabolized in the liver, and is exhaled into the breath as an early peak (typically $<60$ minutes from ingestion) of ${ }^{14} \mathrm{CO}_{2}$. If ${ }^{14} \mathrm{C}-\mathrm{BA}$ is not reabsorbed in the terminal ileum and enters the large intestine, the ${ }^{14} \mathrm{C}-\mathrm{BA}$ is deconjugated by colonic bacteria and, if not absorbed by passive diffusion in the colon, is excreted in stool. This test is no longer widely utilized since development of less complex tests that have no radiation exposure.

The ${ }^{75}$ SeHCAT utilizes a synthetic ${ }^{75}$ selenium homotaurocholic BA that is resistant to bacterial degradation ${ }^{49}$ and passive diffusion..$^{50}$ Like a natural BA, it is either actively absorbed in the terminal ileum or excreted into stool, and unaltered by its passage through the colon. The test involves the patient ingesting a capsule containing ${ }^{75} \mathrm{SeHCAT}$; retention of the isotope in the body at 7 days is measured noninvasively by whole body gamma counter and expressed as a percentage of administered dose. BA may undergo five enterohepatic circulations per day with $\sim 5 \%$ loss in the stool with each circulation; retention rates of 5\%,10\%, and 15\% are used to estimate the relative severity of BAM.

Serum $7 \alpha$-hydroxy-4-cholesten-3-one (C4) measures BA synthesis, 90\% of which is regulated by the rate-limiting enzyme, cholesterol CYP7A1. C4 is a downstream product of CY-

Table 1. Diagnostic Tests for Bile Acid Malabsorption and Their Pros and Cons

\begin{tabular}{|c|c|c|}
\hline BAM diagnosis & Advantages & Disadvantages \\
\hline $\begin{array}{l}\text { Therapeutic trial with } \\
\text { BA sequestrant }\end{array}$ & Clinically applicable, widely used & $\begin{array}{l}\text { Not definitive diagnosis of BAM; nonspecific amelioration of } \\
\text { diarrhea due to other causes; poor compliance with some BA } \\
\text { sequestrants }\end{array}$ \\
\hline${ }^{14} \mathrm{C}$ glycocholate & May identify small bowel bacterial overgrowth & $\begin{array}{l}\text { Radiation exposure, } \beta \text { emission, long } \mathrm{t}_{1 / 2} \\
\text { Varying normal values } \\
\text { Positive breath excretion at } 2-4 \mathrm{hr} \text { does not differentiate BAM } \\
\text { from small bowel bacterial overgrowth } \\
\text { Laborious test method (stool collection) }\end{array}$ \\
\hline \multirow[t]{2}{*}{${ }^{75}$ SeHCAT } & $\begin{array}{l}\gamma \text { Emission, short } t_{1 / 2} \text {, with decreased radiation to } \\
\text { extra-abdominal organs }\end{array}$ & Not available in United States \\
\hline & $\begin{array}{l}\text { Well-defined normal values; level of isotope } \\
\text { retention predicts response to BA sequestrant } \\
\text { Simple test method: } 2 \text { patient visits }\end{array}$ & Radiation exposure \\
\hline \multirow[t]{2}{*}{ Serum $\mathrm{C} 4$} & $\begin{array}{l}\text { No radiation } \\
\text { Normal values reported in adults } \\
\text { Not dependent on age, gender or cholesterol }\end{array}$ & $\begin{array}{l}\text { Fasting sample, diurnal variation } \\
\text { Requires further validation } \\
\text { False-positive in liver disease, treatment with statins and altered } \\
\text { circadian rhythm }\end{array}$ \\
\hline & Simple blood test: 1 patient visit & \\
\hline Serum FGF-19 & No radiation; commercial ELISA assay & Moderate sensitivity and specificity; requires further validation \\
\hline \multirow[t]{2}{*}{ Fecal BA } & No radiation & $\begin{array}{l}\text { Variable daily fecal BA excretion, requires at least } 48 \mathrm{hr} \text { sample } \\
\text { collection }\end{array}$ \\
\hline & Measures total and individual BAs & Cumbersome method (stool collection) \\
\hline $\begin{array}{l}\text { Urine 2-propanol } \\
\text { and acetamide }\end{array}$ & No radiation; urine sample & $\begin{array}{l}\text { Special technology required: Field Asymmetric Ion Mobility } \\
\text { Spectrometer; requires replication and validation }\end{array}$ \\
\hline
\end{tabular}

Updated from Vijayvargiya P, et al. Clin Gastroenterol Hepatol 2013;11:1232-1239. ${ }^{47}$

BAM, bile acid malabsorption; BA, bile acid; ${ }^{75}$ SeHCAT, ${ }^{75}$ selenium homotaurocholic acid test; FGF-19, fibroblast growth factor 19 ; ELISA, enzyme-linked immunosorbent assay. 
P7A1. Serum C4 is a simple blood test, but it requires standardized specimen collection time because of diurnal variability. ${ }^{51}$ Accurate method for measurement uses liquid chromatographytandem mass spectrometry. ${ }^{52}$ The clinical performance of the C4 assay demonstrated a sensitivity of $90 \%$, specificity of $79 \%$, negative predictive value of $98 \%$, and positive predictive value of $74 \%$ when compared to the ${ }^{75} \mathrm{SeHCAT}$ test. The high negative predictive value makes the assay attractive as a screening test to rule out BAM. ${ }^{53} \mathrm{C} 4$ was unrelated to age, gender or serum cholesterol when analyzed against potential covariates. ${ }^{53}$ When compared to elevated 48-hour fecal BA excretion, elevated serum C4 did not identify phenotype differences (such as increased fecal fat and colonic transit) among patients with IBS$\mathrm{D}$, other than documenting the increased fecal BAs among those with elevated serum $\mathrm{C} 4$, defined as $>47.1 \mathrm{ng} / \mathrm{mL} .{ }^{46}$ In summary, serum C4 test is applicable to a majority of patients, but requires further clinical validation including responsiveness to BA sequestrants therapy or FXR agonists in patients with BAM.

Fecal measurements to quantify total and individual fecal BAs are technically cumbersome and not widely available. ${ }^{10,38,46}$ These Mayo Clinic studies showed that IBS-D is associated with higher serum $\mathrm{C} 4$, higher total fecal BA, and increased secretory BAs (e.g., CDCA, DCA). In addition, high fecal BA excretion was associated with a more significant IBS-D phenotype, characterized by higher fecal fat and a trend toward accelerated colonic transit. ${ }^{46}$ Indeed, fecal BA excretion and colonic transit were validated as biomarkers that identified mechanisms that could be targets of treatment in patients with IBS-D. ${ }^{54}$ Excretion of $>2,337 \mu \mathrm{mol}$ per 48 hours (upper limit of normal) is used as an index of BAM. ${ }^{46,54}$

An enzymatic $3 \alpha$-steroid dehydrogenase assay indirectly measures fecal BA. $3 \alpha$-Steroid dehydrogenase is used to oxidize deconjugated BAs and produces $\mathrm{NADH}$, which is then measured biochemically. This method requires proper stereotactic alignment of enzyme and substrate and with a variety of conjugations (sulfonation, glucuronidation) of BAs while they are in the small intestine. This method would lack precision if it was used to measure concentrations of BAs in small bowel fluid or ileostomy effluent. In addition, because it does not assess BAs with hydroxyl groups in the $\beta$-configuration, it tends to underestimate total BAs.

\section{Indirect measurements of bile acids}

Serum FGF-19 is a useful screening test for BAD, ${ }^{39}$ given the inverse relationship between C4 and FGF-19 originally described by Walters et al. ${ }^{9}$ It has been validated in studies using ${ }^{75}$ SeHCAT retention as the gold standard ${ }^{55}$ and by comparisons with serum $C 4 .{ }^{56}$ In the study of Pattni et al..$^{56}$ of 258 patients, sensitivity and specificity of FGF 19 at $145 \mathrm{pg} / \mathrm{mL}$ for detecting a C4 level >28 ng/mL were 58\% and 79\%, respectively, and for C4 >60 ng/mL (denoting high BA synthesis), the sensitivity and specificity of FGF-19 were $74 \%$ and $72 \%$, respectively. ${ }^{55}$ The attraction of this diagnostic method is the ease of the enzymelinked immunosorbent assay and the measurements based on a morning, fasting serum sample. Further validation studies, including responsiveness to therapy of BAM, are eagerly awaited.

Urine 2-propanol and acetamide ${ }^{57}$ are volatile organic compounds produced by the gut bacterial cleavage of BAs. This method uses an electronic nose (that mimics the biological olfactory system ${ }^{58}$ and a Field Asymmetric Ion Mobility Spectrometer that separates ionized molecules based on their different mobilities in a high electric field. ${ }^{59}$ These volatile organic compounds were detected in urine of 23 patients with BAD (confirmed by ${ }^{75} \mathrm{SeHCAT}$ ), in contrast to 42 patients with ulcerative colitis and 45 healthy controls. Further studies are awaited.

\section{MANAGEMENT OF BILE ACID DIARRHEA}

\section{Intraluminal bile acid binders}

Cholestyramine and colestipol are generally considered firstline treatment for $\mathrm{BAD}$; however, poor palatability results in low patient compliance. ${ }^{60}$ Several open label studies have recently demonstrated efficacy of these BA sequestrants in patients with IBS-D, especially those with evidence of BAM. ${ }^{61,62}$ For example, colestipol treatment improved IBS symptoms (IBS severity scoring system $220 \pm 109$ vs $277 \pm 106$; $p<0.01$ ), and 15 of 27 patients also fulfilled criteria for treatment response (adequate relief $\geq 50 \%$ of weeks 5 to 8), suggesting benefit both in bowel symptoms and global symptoms.

Alternatives are being tested, even though there are no large clinical trials specifically for the indication of BAD. Thus, patients may prefer colesevelam at a dose of up to $1.875 \mathrm{~g}$, twice a day. In a pharmacodynamics study of 24 unselected patients with IBS-D, ${ }^{63}$ emptying of the ascending colon took an average of 4 hours longer in patients given colesevelam (1.875 g, twice a day) compared with placebo, treatment effect was significantly associated with baseline serum C4 levels, and colesevelam caused greater ease of stool passage and somewhat firmer stool consistency. In an unpublished open-label study (Camilleri 2014, unpublished) of the same dose of colesevelam in 12 IBS-D patients with elevated fecal BA excretion, we have also shown that colesevelam sequestered BAs and resulted in significantly firmer stool consistency.

\section{Experimental agents inhibiting bile acid diarrhea by cel- lular mechanisms}

FGF-19 production is stimulated by the FXR agonist, obeticholic acid, ${ }^{64}$ which may potentially reverse the FGF-19 deficiency postulated in BAM that leads to excessive hepatocyte BA synthesis. This treatment has been associated with improved stool frequency and consistency in a preliminary study of patients with BAD. ${ }^{65}$ Another FXR agonist, GW4064, attenuated $\mathrm{Cl}^{-}$secretory responses to both $\mathrm{Ca}^{2+}$ and cAMP-dependent agonists, and may be efficacious in the treatment of BAD through 
antisecretory actions on the colonic epithelium. ${ }^{66}$

\section{CONCLUSION AND FUTURE DIRECTION}

The pioneering work conducted 40 years ago by giants in this field (Drs. Alan Hofmann, Donald Small, Hans Fromm, and Vinton Chadwick) is finally going to have an impact beyond the patients with ileal resection or ileal Crohn's disease. BA diarrhea is finally appreciated as a significant cause of functional, otherwise unexplained, chronic diarrhea in about one-third of such patients. The availability of simple diagnostic stool tests (fecal BA excretion performed at the time of fecal fat measurement) and, even more applicable, serum or urine tests will enhance the ability of physicians to diagnose this eminently treatable disorder.

In the future, BA sequestration with tablet formulations that are associated with higher compliance or Farnesoid X receptor agonists will impact the care of patients and likely reduce overall healthcare costs by reducing the need for expensive tests like colonoscopy and biopsies or treatments like biologic agents in patients with Crohn's disease.

\section{CONFLICTS OF INTEREST}

No potential conflict of interest relevant to this article was reported.

\section{ACKNOWLEDGEMENTS}

Dr. Camilleri is supported by grant R01-DK92179 from National Institutes of Health.

\section{REFERENCES}

1. Hofmann AF, Small DM. Detergent properties of bile salts: correlation with physiological function. Annu Rev Med 1967;18:333376.

2. Ridlon JM, Kang DJ, Hylemon PB. Bile salt biotransformations by human intestinal bacteria. J Lipid Res 2006;47:241-259.

3. Hofmann AF. The syndrome of ileal disease and the broken enterohepatic circulation: cholerhetic enteropathy. Gastroenterology 1967;52:752-757.

4. Caspary WF, Zavada I, Reimold W, Deuticke U, Emrich D, Willms B. Alteration of bile acid metabolism and vitamin-B12-absorption in diabetics on biguanides. Diabetologia 1977;13:187-193.

5. Scarpello JH, Hodgson E, Howlett HC. Effect of metformin on bile salt circulation and intestinal motility in type 2 diabetes mellitus. Diabet Med 1998;15:651-656.

6. Miles JM, Camilleri M, Vella A. Effects of metformin on bile acid metabolism in type 2 diabetes. Diabetes 2014;63(Suppl 1):A285A286.

7. Camilleri M. Physiological underpinnings of irritable bowel syn- drome: neurohormonal mechanisms. J Physiol 2014;592(Pt 14): 2967-2980.

8. Lundåsen T, Gälman C, Angelin B, Rudling M. Circulating intestinal fibroblast growth factor 19 has a pronounced diurnal variation and modulates hepatic bile acid synthesis in man. J Intern Med 2006;260:530-536.

9. Walters JR, Tasleem AM, Omer OS, Brydon WG, Dew T, le Roux CW. A new mechanism for bile acid diarrhea: defective feedback inhibition of bile acid biosynthesis. Clin Gastroenterol Hepatol 2009;7:1189-1194.

10. Wong BS, Camilleri M, Carlson P, et al. Increased bile acid biosynthesis is associated with irritable bowel syndrome with diarrhea. Clin Gastroenterol Hepatol 2012;10:1009-1015.

11. Rao AS, Wong BS, Camilleri M, et al. Chenodeoxycholate in females with irritable bowel syndrome-constipation: a pharmacodynamic and pharmacogenetic analysis. Gastroenterology 2010; 139:1549-1558.

12. Montagnani M, Love MW, Rössel P, Dawson PA, Qvist P. Absence of dysfunctional ileal sodium-bile acid cotransporter gene mutations in patients with adult-onset idiopathic bile acid malabsorption. Scand J Gastroenterol 2001;36:1077-1080.

13. Montagnani M, Abrahamsson A, Gälman C, et al. Analysis of ileal sodium/bile acid cotransporter and related nuclear receptor genes in a family with multiple cases of idiopathic bile acid malabsorption. World J Gastroenterol 2006;12:7710-7714.

14. Bajor A, Kilander A, Fae A, et al. Normal or increased bile acid uptake in isolated mucosa from patients with bile acid malabsorption. Eur J Gastroenterol Hepatol 2006;18:397-403.

15. Sadik R, Abrahamsson H, Ung KA, Stotzer PO. Accelerated regional bowel transit and overweight shown in idiopathic bile acid malabsorption. Am J Gastroenterol 2004;99:711-718.

16. Valdés Olmos R, den Hartog Jager F, Hoefnagel C, Taal B. Effect of loperamide and delay of bowel motility on bile acid malabsorption caused by late radiation damage and ileal resection. Eur J Nucl Med 1991;18:346-350.

17. Yeoh EK, Horowitz M, Russo A, Muecke T, Robb T, Chatterton BE. Gastrointestinal function in chronic radiation enteritis: effects of loperamide-N-oxide. Gut 1993;34:476-482.

18. Wong BS, Camilleri M, Carlson PJ, et al. A Klotho $\beta$ variant mediates protein stability and associates with colon transit in irritable bowel syndrome with diarrhea. Gastroenterology 2011;140:19341942.

19. Camilleri M, Klee EW, Shin A, et al. Irritable bowel syndromediarrhea: characterization of genotype by exome sequencing, and phenotypes of bile acid synthesis and colonic transit. Am J Physiol Gastrointest Liver Physiol 2014;306:G13-G26.

20. Kawamata Y, Fujii R, Hosoya M, et al. A G protein-coupled receptor responsive to bile acids. J Biol Chem 2003;278:9435-9440.

21. Ward JB, Mroz MS, Keely SJ. The bile acid receptor, TGR5, regulates basal and cholinergic-induced secretory responses in rat colon. Neurogastroenterol Motil 2013;25:708-711.

22. Poole DP, Godfrey C, Cattaruzza F, et al. Expression and function 
of the bile acid receptor GpBAR1 (TGR5) in the murine enteric nervous system. Neurogastroenterol Motil 2010;22:814-825.

23. Alemi F, Poole DP, Chiu J, et al. The receptor TGR5 mediates the prokinetic actions of intestinal bile acids and is required for normal defecation in mice. Gastroenterology 2013;144:145-154.

24. Camilleri M, Shin A, Busciglio I, et al. Genetic variation in GPBAR1 predisposes to quantitative changes in colonic transit and bile acid excretion. Am J Physiol Gastrointest Liver Physiol 2014; 307:G508-G516

25. Bunnett NW. Neuro-humoral signalling by bile acids and the TGR5 receptor in the gastrointestinal tract. J Physiol 2014;592: 2943-2950.

26. Chadwick VS, Gaginella TS, Carlson GL, Debongnie JC, Phillips SF, Hofmann AF. Effect of molecular structure on bile acid-induced alterations in absorptive function, permeability, and morphology in the perfused rabbit colon. J Lab Clin Med 1979;94:661-674.

27. Conley DR, Coyne MJ, Bonorris GG, Chung A, Schoenfield LJ. Bile acid stimulation of colonic adenylate cyclase and secretion in the rabbit. Am J Dig Dis 1976;21:453-458.

28. Ao M, Sarathy J, Domingue J, Alrefai WA, Rao MC. Chenodeoxycholic acid stimulates $\mathrm{Cl}(-)$ secretion via cAMP signaling and increases cystic fibrosis transmembrane conductance regulator phosphorylation in T84 cells. Am J Physiol Cell Physiol 2013;305: C447-C456.

29. Alrefai WA, Saksena S, Tyagi S, Gill RK, Ramaswamy K, Dudeja PK. Taurodeoxycholate modulates apical Cl-/OH- exchange activity in Caco2 cells. Dig Dis Sci 2007;52:1270-1278.

30. Camilleri M, Murphy R, Chadwick VS. Dose-related effects of chenodeoxycholic acid in the rabbit colon. Dig Dis Sci 1980;25:433438.

31. Barcelo A, Claustre J, Toumi F, et al. Effect of bile salts on colonic mucus secretion in isolated vascularly perfused rat colon. Dig Dis Sci 2001;46:1223-1231.

32. Bampton PA, Dinning PG, Kennedy ML, Lubowski DZ, Cook IJ. The proximal colonic motor response to rectal mechanical and chemical stimulation. Am J Physiol Gastrointest Liver Physiol 2002;282:G443-F449.

33. Hofmann AF, Poley JR. Cholestyramine treatment of diarrhea associated with ileal resection. N Engl J Med 1969;281:397-402.

34. Hofmann AF, Poley JR. Role of bile acid malabsorption in pathogenesis of diarrhea and steatorrhea in patients with ileal resection. I. Response to cholestyramine or replacement of dietary long chain triglyceride by medium chain triglyceride. Gastroenterology 1972;62:918-934.

35. Poley JR, Hofmann AF. Role of fat maldigestion in pathogenesis of steatorrhea in ileal resection. Fat digestion after two sequential test meals with and without cholestyramine. Gastroenterology 1976;71:38-44.

36. Wedlake L, A'Hern R, Russell D, Thomas K, Walters JR, Andreyev HJ. Systematic review: the prevalence of idiopathic bile acid malabsorption as diagnosed by SeHCAT scanning in patients with diarrhoea-predominant irritable bowel syndrome. Aliment Phar- macol Ther 2009;30:707-717.

37. Gracie DJ, Kane JS, Mumtaz S, Scarsbrook AF, Chowdhury FU, Ford AC. Prevalence of, and predictors of, bile acid malabsorption in outpatients with chronic diarrhea. Neurogastroenterol Motil 2012;24:983-e538.

38. Shin A, Camilleri M, Vijayvargiya P, et al. Bowel functions, fecal unconjugated primary and secondary bile acids, and colonic transit in patients with irritable bowel syndrome. Clin Gastroenterol Hepatol 2013;11:1270-1275.

39. Walters JR, Pattni SS. Managing bile acid diarrhoea. Therap Adv Gastroenterol 2010;3:349-357.

40. Sayin SI, Wahlström A, Felin J, et al. Gut microbiota regulates bile acid metabolism by reducing the levels of tauro-beta-muricholic acid, a naturally occurring FXR antagonist. Cell Metab 2013;17: 225-235.

41. Zhao Y, Wu J, Li JV, Zhou NY, Tang H, Wang Y. Gut microbiota composition modifies fecal metabolic profiles in mice. J Proteome Res 2013;12:2987-2999.

42. Ridlon JM, Alves JM, Hylemon PB, Bajaj JS. Cirrhosis, bile acids and gut microbiota: unraveling a complex relationship. Gut Microbes 2013;4:382-387.

43. Ou J, Carbonero F, Zoetendal EG, et al. Diet, microbiota, and microbial metabolites in colon cancer risk in rural Africans and African Americans. Am J Clin Nutr 2013;98:111-120.

44. Duboc H, Rajca S, Rainteau D, et al. Connecting dysbiosis, bileacid dysmetabolism and gut inflammation in inflammatory bowel diseases. Gut 2013;62:531-539.

45. Duboc H, Rainteau D, Rajca S, et al. Increase in fecal primary bile acids and dysbiosis in patients with diarrhea-predominant irritable bowel syndrome. Neurogastroenterol Motil 2012;24:513-520.

46. Camilleri M, Busciglio I, Acosta A, et al. Effect of increased bile acid synthesis or fecal excretion in irritable bowel syndromediarrhea. Am J Gastroenterol 2014;109:1621-1630.

47. Vijayvargiya P, Camilleri M, Shin A, Saenger A. Methods for diagnosis of bile acid malabsorption in clinical practice. Clin Gastroenterol Hepatol 2013;11:1232-1239.

48. Fromm H, Hofmann AF. Breath test for altered bile-acid metabolism. Lancet 1971;2:621-625.

49. Thaysen EH, Orholm M, Arnfred T, Carl J, Rødbro P. Assessment of ileal function by abdominal counting of the retention of a gamma emitting bile acid analogue. Gut 1982;23:862-865.

50. Williams AJ, Merrick MV, Eastwood MA. Idiopathic bile acid malabsorption: a review of clinical presentation, diagnosis, and response to treatment. Gut 1991;32:1004-1006.

51. Gälman C, Arvidsson I, Angelin B, Rudling M. Monitoring hepatic cholesterol 7alpha-hydroxylase activity by assay of the stable bile acid intermediate 7alpha-hydroxy-4-cholesten-3-one in peripheral blood. J Lipid Res 2003;44:859-866.

52. Camilleri M, Nadeau A, Tremaine WJ, et al. Measurement of serum 7alpha-hydroxy-4-cholesten-3-one (or 7alphaC4), a surrogate test for bile acid malabsorption in health, ileal disease and irritable bowel syndrome using liquid chromatography-tandem mass spec- 
trometry. Neurogastroenterol Motil 2009;21:734-e43.

53. Sauter GH, Münzing W, von Ritter C, Paumgartner G. Bile acid malabsorption as a cause of chronic diarrhea: diagnostic value of 7alpha-hydroxy-4-cholesten-3-one in serum. Dig Dis Sci 1999;44: 14-19.

54. Camilleri M, Shin A, Busciglio I, et al. Validating biomarkers of treatable mechanisms in irritable bowel syndrome. Neurogastroenterol Motil 2014;26:1677-1685.

55. Pattni SS, Brydon WG, Dew T, et al. Fibroblast growth factor 19 in patients with bile acid diarrhoea: a prospective comparison of FGF19 serum assay and SeHCAT retention. Aliment Pharmacol Ther 2013;38:967-976.

56. Pattni SS, Brydon WG, Dew T, Walters JR. Fibroblast growth factor 19 and 7alpha-hydroxy-4-cholesten-3-one in the diagnosis of patients with possible bile acid diarrhea. Clin Transl Gastroenterol 2012;3:e18.

57. Covington JA, Westenbrink EW, Ouaret N, et al. Application of a novel tool for diagnosing bile acid diarrhoea. Sensors 2013;13: 11899-11912.

58. Wilson $\mathrm{AD}$, Baietto M. Advances in electronic-nose technologies developed for biomedical applications. Sensors 2011;11:11051176.

59. Arasaradnam RP, Ouaret N, Thomas MG, et al. Evaluation of gut bacterial populations using an electronic e-nose and field asymmetric ion mobility spectrometry: further insights into 'fermenton- omics'. J Med Eng Technol 2012;36:333-337.

60. Halilbasic E, Claudel T, Trauner M. Bile acid transporters and regulatory nuclear receptors in the liver and beyond. J Hepatol 2013; 58:155-168.

61. Stotzer PO, Abrahamsson H, Bajor A, Sadik R. Effect of cholestyramine on gastrointestinal transit in patients with idiopathic bile acid diarrhea: a prospective, open-label study. Neuroenterology 2013;2:Article ID 235657.

62. Bajor A, Törnblom H, Rudling M, Ung KA, Simrén M. Increased colonic bile acid exposure: a relevant factor for symptoms and treatment in IBS. Gut 2015;64:84-92.

63. Odunsi-Shiyanbade ST, Camilleri M, McKinzie S, et al. Effects of chenodeoxycholate and a bile acid sequestrant, colesevelam, on intestinal transit and bowel function. Clin Gastroenterol Hepatol 2010;8:159-165.

64. Zhang JH, Nolan JD, Kennie SL, et al. Potent stimulation of fibroblast growth factor 19 expression in the human ileum by bile acids. Am J Physiol Gastrointest Liver Physiol 2013;304:G940-G948.

65. Johnston IM, Nolan JD, Dew T, Shapiro D, Walters JR. A new therapy for chronic diarrhea? A proof of concept study of the FXR agonist obeticholic acid in patients with primary bile acid diarrhea. Gastroenterology 2013;144(Suppl 1):S-60.

66. Mroz MS, Keating N, Ward JB, et al. Farnesoid X receptor agonists attenuate colonic epithelial secretory function and prevent experimental diarrhoea in vivo. Gut 2014;63:808-817. 